\title{
Effects of cigarette smoking on the serum concentration of lung surfactant protein A (SP-A)
}

\author{
K. Kida, H. Oda, Y. Yamano, J. Kagawa
}

Effects of cigarette smoking on the serum concentration of lung surfactant protein A (SP-A). K. Kida, H. Oda, Y. Yamano, J. Kagawa. CERS Journals Ltd 1997.

ABSTRACT: We have tested the hypothesis that serum surfactant protein A (SPA) production may be affected by cigarette smoke exposure, and that alterations in serum levels may reflect smoking habits.

A total of 52 subjects were divided into the following two groups: active smokers (Group A; $n=23$ ); and nonsmokers (Group B; $n=29$ ). The assessment of smoking habit was determined by self-report, carbon monoxide concentration in expired air, and cotinine concentration in urine.

Serum SP-A was compared in both groups and was found to be higher in Group A (active smokers) $(\mathbf{p}<0.002)$.

We conclude that surfactant protein A levels are increased in the serum of smokers. However, it was found that this is not a sensitive discriminating factor to separate smokers from nonsmokers.

Eur Respir J 1997; 10: 2124-2126.
Pulmonary Division, Tokyo Metropolitan Geriatric Hospital, Tokyo, Japan, and Dept of Hygiene and Public Health, Tokyo Women's Medical College, Tokyo, Japan.

\section{Correspondence: K. Kida}

Pulmonary Division

Tokyo Metropolitan Geriatric Hospital 35-2 Sakae-cho

Itabashi

Tokyo

Japan-173

Keywords: Healthy male, serum surfactant protein A, smoking habit

Received: October 101994

Accepted after revision May 311997
Surfactant is a complex substance comprising at least four specific proteins with a unique phospholipid composition [1]. The unique surfactant-associated proteins have been identified as surfactant proteins A (SP-A), B (SP-B), C (SP-C) and D (SP-D) [1]. Recently, KUROKI et al. [2] showed that SP-A appears in the bloodstream as a complex with immunoglobulin, and that increased concentrations are found in the serum of patients with idiopathic pulmonary fibrosis (IPF) and alveolar proteinosis. There is evidence that smoking is a potentiating factor in IPF, and biochemical studies suggest that surfactant function in smokers is impaired $[3,4]$.

In this study, we hypothesized that SP-A production may be affected by cigarette smoke exposure, and that alterations in serum levels may reflect smoking habit.

In this context, serum SP-A levels in healthy male cigarette smoking and nonsmoking office workers were compared.

\section{Methods}

\section{Subjects}

Sixty male office workers, both smokers and nonsmokers, aged 20-50 yrs, were selected at random. After being informed in detail of the study purpose and procedures, all subjects answered a questionnaire about their respiratory symptoms, past medical history, current medications and detailed smoking habits. Subjects with a history of wheezing, persistent cough or expectoration, present or previous cardiopulmonary disease, or those on current medication were excluded from the study.
Finally, a total of 52 subjects were entered into the study. All tests were performed on one Wednesday or Thursday, during working-time, between 14.00 and $16.00 \mathrm{~h}$. Current smokers were not permitted to smoke for at least $1 \mathrm{~h}$ prior to testing.

A total of 52 subjects fulfilled the criteria and were included in the study. According to smoking habit, the subjects were divided into active smokers (Group A; $\mathrm{n}=23$ ) and nonactive smokers (Group B; $n=29$ ). Twenty of those in Group B had never smoked and nine were exsmokers who had ceased smoking more than 3 yrs earlier.

Ages ranged 23-47 yrs, Group A ( $n=23$; age (mean \pm SEM) $33 \pm 8$ yrs) and Group B ( $=29 ; 36 \pm 9$ yrs $)$.

\section{Measurements}

Pulmonary function test. Pulmonary function testing of forced expiratory volume in one second (FEV1), FEV1 $\%$ predicted, and FEV1/vital capacity (VC) were performed with a spirometer (Chest HI-501, Chest Co., Tokyo, Japan). Triplicate measurements were obtained for each subject.

Urine cotinine. The first approximately $10 \mathrm{~mL}$ of urine expelled from each subject was used to measure cotinine. The urine was stored at $-80^{\circ} \mathrm{C}$ until used. The concentration of cotinine was measured by high-performance liquid chromatography (HPLC) by the method of HORSTMANN et al. [5], with minor modification. Briefly, $1 \mathrm{~mL}$ of 5 $\mathrm{N} \mathrm{NaOH}$ and $4 \mathrm{~mL}$ of chloroform were added to $5 \mathrm{~mL}$ of the urine sample, and the mixture was centrifuged for $10 \mathrm{~min}$. The organic layer was then redissolved in $250 \mu \mathrm{L}$ of dichloromethane for HPLC analysis. 
Chromatographic analysis was performed at $40^{\circ} \mathrm{C}$ at a flow rate of $1-2 \mathrm{~mL} \cdot \mathrm{min}^{-1}$. The concentration of cotinine in the urine sample was corrected for creatinine concentration in the same sample (COT/CRE ratio). For the assay of urinary creatinine, the level in $150 \mu \mathrm{L}$ of urine was measured using as automated clinical chemical analyser (550 Express; Ciba-Corning Instruments, New York, USA). Reproducibility and coefficients of variation in the urinary cotinine and creatinine analysis were obtained by duplicate analysis.

Carbon monoxide in expired air. Each subject was asked to take a deep breath, hold it for $20 \mathrm{~s}$, and then breathe out steadily and gently through the mouthpiece of the equipment described below. The concentration of endtidal expired air carbon monoxide was measured with Mini and Micro Smokerlyzers (Bedford Technical Instruments Ltd, Manchester, UK). The equipment was calibprated daily during use with a mixture of 100 ppm carbon monoxide in air.

Surfactant protein A. The SP-A concentration in serum samples was measured according to KUROKI et al. [2], with minor modifications as follows. The serum samples were diluted from 50 to $200 \mu \mathrm{L}$ in buffer A (10 $\mathrm{mM}$ phosphate buffered saline (PBS), $\mathrm{pH} 7.2$, containing $1.5 \%(\mathrm{w} / \mathrm{v})$ sodium dodecyl sulphate (SDS) and $3 \%$ (v/v) Triton X-100). Two hundred microlitres of monoclonal antibody prepared against human SP-A (provided by Y. Kuroki and T. Akino, Sapporo Medical College, Japan) and labelled with horseradish peroxidase dissolved in buffer B (10 mM PBS, pH 7.4, containing $0.25 \%(\mathrm{w} / \mathrm{v})$ skimmed milk), was added and mixed thoroughly. A plastic bead coated with the monoclonal antibody to SP-A was added to each tube containing the above mixture, and the assay tubes were incubated at $37^{\circ} \mathrm{C}$ for $90 \mathrm{~min}$.

After incubation, the beads were washed three times with distilled water and added to $400 \mu \mathrm{L}$ of substrate solution $(0.1 \mathrm{M}$ phosphate-citrate buffer, $\mathrm{pH} 4.0$, containing $5 \mathrm{mM} \mathrm{H} \mathrm{H}_{2}$ and $0.06 \%(\mathrm{w} / \mathrm{v})$ tetramethylbenzidine). The mixtures were incubated at $37^{\circ} \mathrm{C}$ for $30 \mathrm{~min}$ and the reaction was stopped by the addition of $1 \mathrm{~mL}$ of $1 \mathrm{~N}$ sulphuric acid. The absorbance of each tube was measured at $450 \mathrm{~nm}$. By these modifications, the assay system was able to detect SP-A in the concentration range of $2.5-250 \mathrm{ng} \cdot \mathrm{mL}^{-1}$, whereas the previous range of detection was $12.5-100 \mathrm{ng} \cdot \mathrm{mL}^{-1}$ [2]. Reproducibility and coefficients of variation were obtained by duplicate analysis.

\section{Statistical analysis}

The significance of differences between two groups was determined by unpaired Student's t-test. A p-value of less than 0.05 was regarded as significant. Results are expressed as mean \pm SEM.

\section{Results}

Age and spirometric data, including FEV1, FEV1 \% pred, $\mathrm{VC}$, and $\mathrm{FEV} 1 / \mathrm{VC}$, were not significantly differ-

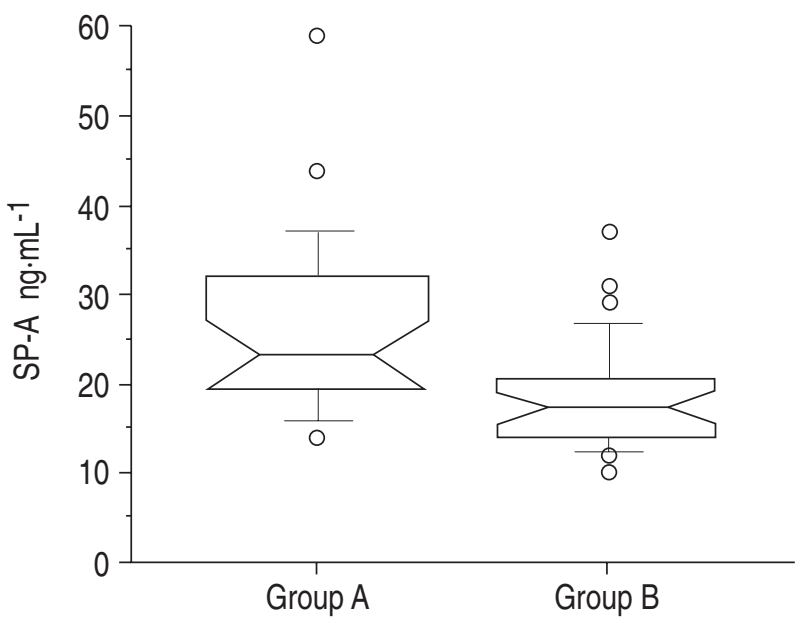

Fig. 1. - Serum surfactant protein (SP-A) concentration in smokers (Group A) and nonsmokers (Group B). Data are shown by box plot. Each plot is composed of five horizontal lines that display the 10th, 25th, 50th, 75th and 90th percentiles of a variable. Group A: smokers $(n=23)$; Group B: nonsmokers $(n=29)$. Group A showed higher serum SP-A concentrations than Group B $(\mathrm{p}<0.002)$.

ent between the two groups and all were within normal limits for male subjects of the same age (data not shown).

Serum SP-A levels were significantly higher in active smokers (Group A $26.22 \pm 2.14 \mathrm{ng} \cdot \mathrm{mL}^{-1}$ ) than in nonsmokers (Group B; $\left.18.35 \pm 1.12 \mathrm{ng} \cdot \mathrm{mL}^{-1}\right)(\mathrm{p}<0.002)$, as shown by the box plot in figure 1 .

The SP-A concentration increased in parallel with increased end-tidal CO ( $\mathrm{Y}=1.229+7.179 \mathrm{e}^{-3 \mathrm{X}} ; \mathrm{r}=0.449$; $\mathrm{p}<0.01)$. The SP-A concentrations were also significantly correlated with the COT/CRE ratio $(\mathrm{Y}=1.271+$ $\left.6.971 \mathrm{e}^{-5 \mathrm{X}} ; \mathrm{r}=0.359 ; \mathrm{p}<0.01\right)$.

Cotinine concentration in the urine, corrected for creatinine concentration (COT/CRE), was significantly higher in Group A $\left(1125.39 \pm 181.79 \mathrm{ng} \cdot \mathrm{mg}^{-1} \mathrm{CRE}\right)$ than Group B $\left(6.74 \pm 1.11 \mathrm{ng} \cdot \mathrm{mg}^{-1} \mathrm{CRE}\right.$; $\left.\mathrm{p}<0.0001\right)$. Similarly, the carbon monoxide concentration in expired-air (endtidal CO) was higher in Group A $(20.22 \pm 1.73 \mathrm{ppm})$ than Group B (4.00 \pm 0.22 ppm; p<0.0001).

\section{Discussion}

This study showed that SP-A, the major surfactant protein, is increased in serum of smokers. The molecular mass of SP-A ranges $26-36 \mathrm{kDa}$ because of variable glycosylation [6]. This protein binds phosphatidylcholine and is thought to promote the formation of tubular myelin-like structures from newly secreted phospholipids [6], and to enhance the adsorption of phospholipids to the air/liquid interface in co-operation with other surfactant proteins. Thus, SP-A has a role in regulating the metabolic pathways of secretion and uptake of surfactant between alveolar type II cells and alveolar spaces [6].

In the present study, SP-A was measured by an enzymelinked immunosorbent assay (ELISA), using monoclonal antibodies against human SP-A developed by KUROKI et al. [2]. The ELISA has been applied clinically to measure SP-A as a marker for surfactant in amniotic fluid [7], sputum [8], pleural effusion [9], bronchoalveolar lavage fluid [10], and serum [2]. 
A low yield of surfactant phospholipids from smokers was first described by FINLEY et al. [3] and subsequently by Low et al. [4]. An abnormal surface activity of lavage fluid from smokers has been described $[3,11]$. Earlier studies by FINLEY et al. [3] suggested no qualitative differences in the lipid analyses of surfactant from smokers and nonsmokers, but the total lipid content and, in particular, the lecithin content, was seven times less in smokers. Similarly, data obtained by Low et al. [4] revealed that lavage fluid samples from smokers contain significantly lower ratios of lipid phosphorus to protein and lower albumin normalization values than those of nonsmokers. However, these earlier studies did not refer to qualitative changes in surfactant proteins, a factor that should be examined since recent data suggest independent pathways for SP-A and saturated phosphatidylcholine secretion [12]. The present data show that the serum SP-A concentration is significantly higher in healthy male current smokers than in nonsmokers $(\mathrm{p}<$ 0.002); however, it was found that serum SP-A is not a sensitive indicator for discriminating smoking habit.

It has been shown that SP-A appears in the bloodstream of patients with idiopathic pulmonary fibrosis (IPF) and pulmonary alveolar proteinosis (PAP) in a nonspecific complex with immunoglobulin $\mathrm{G}$ and $\mathrm{M}$ [2], although the precise mechanism through which SP-A and immunoglobulin complexes appear in IPF and PAP is not known. One possibility is that an influx of serum protein into alveolar airspaces occurs in IPF or PAP; therefore, it is possible that there is a corresponding efflux of SP-A from alveolar type II cells into the bloodstream, where it forms complexes. Also, it raises the possibility that some specific proteins present in the bloodstream of IPF or PAP patients bind to SP-A, as suggested by AKINO [13]. All these findings suggest that increased serum SP-A concentration is not a specific phenomenon in IPF or PAP.

It is necessary to consider whether serum SP-A concentration is superior to other known biological markers, such as cotinine or end-tidal carbon monoxide concentration, for discriminating smoking exposure. Our study suggests that this is not the case. At present, the precise factors that influence serum SP-A concentration with respect to smoking habit are unknown. A half-life value of $6.5 \mathrm{~h}$ for SP-A in the airspaces has been noted [12]; the decay time of serum SP-A is not known. Therefore, it is possible that the decay time is lengthened in smokers, and this leads to higher serum SP-A levels. Another possibility is that the increase in serum SP-A might arise from increased alveolar liquid permeability due to surfactant inactivation. This would be consistent with changes seen in sarcoidosis, in which the concentration of SP-A in the bronchoalveolar lavage fluid is markedly higher than in control subjects [14], and may also be supported by the observation of increased alveolar permeability in smokers as determined by technetium clearance [15].
In summary, the current study shows that serum surfactant protein A levels are increased in current smokers as compared with nonsmokers. The mechanism and implications for this observation remain unknown at present.

Acknowledgement: The authors would like to thank M. Dooley-Ohto for her assistance with the manuscript.

\section{References}

1. Possmayer F. A proposed nomenclature for pulmonary surfactant associated proteins. Am Rev Respir Dis 1988; 138: 990-998.

2. Kuroki Y, Tsutahara S, Shijubo N, et al. Elevated levels of lung surfactant protein A in sera from patients with idiopathic pulmonary fibrosis and pulmonary alveolar proteinosis. Am Rev Respir Dis 1993; 147: 723-729.

3. Finley TN, Ladman AJ. Low yield of pulmonary surfactant in cigarette smokers. $N$ Engl J Med 1972; 286: 223-227.

4. Low RB, Davis GS, Giancola MS. Biochemical analyses of bronchoalveolar lavage fluids of healthy human volunteers, smokers and nonsmokers. Am Rev Respir Dis 1978; 118: 863-875.

5. Horstmann M. Simple high-performance liquid chromatographic method for rapid determination of nicotine and cotinine in urine. J Chromatogr 1985; 344: 391-396.

6. Hawgood S. Surfactant: composition, structure, and metabolism. In: Crystal RG, West JB, Barnes PJ, Cherniack NS, eds. The Lung: Scientific Foundation, New York, Raven Press, Ltd, 1991; pp. 247-261.

7. Kuroki Y, Takahashi H, Fukuda Y, et al. Two-site "simultaneous" immunoassay with monoclonal antibodies for the determination of the surfactant apoproteins in human amniotic fluid. Pediatr Res 1985; 19: 1017-1020.

8. Masuda T, Shimura S, Sasaki H, Takishima T. Surfactant protein A concentration in sputum for diagnosis of pulmonary alveolar proteinosis. Lancet 1991; 377: 580-582.

9. Shijubo S, Tautahara S, Hirasawa M, et al. Pulmonary surfactant protein A in pleural effusions. Cancer 1992; 69: 2905-2909.

10. McCormack FX, King JTE, Voelker DR, Robinson PC, Mason RJ. Idiopathic pulmonary fibrosis: abnormalities in the bronchoalveolar lavage content of surfactant protein A. Am Rev Respir Dis 1991; 144: 160-166.

11. Cook WD, Webb WR. Surfactant in chronic smokers. Ann Thorac Surg 1966; 2: 327-333.

12. Ueda T, Ikegami M, Jobe AH. Clearance of surfactant protein A from rabbit lungs. Am J Respir Cell Mol Biol 1995; 12: 89-94.

13. Akino T. Biochemical and clinical aspects of pulmonary surfactant proteins. J Jap Thorac Soc 1992; 30 (Suppl.): $5-14$.

14. Jones JG, Minty BD, Lawler P, Hulands G, Crawley JCW, Veall N. Increased alveolar epithelial permeability in cigarette smokers. Lancet 1980; 8151: 66-67.

15. Hamm H, Luhrs J, Guzman Y, et al. Elevated surfactant protein A in bronchoalveolar lavage fluids from sarcoidosis and hypersensitivity pneumonitis patients. Chest 1994; 106: 1766-1770. 